\title{
Determination of sultamicillin in bulk and pharmaceutical preparations via derivatization with NBD-Cl by spectrophotometry
}

\author{
Elif Özdemir ${ }^{1}$ (D), Duygu Tașkın² (D), Sıdıka Sungur ${ }^{1}$ (D) \\ 'Istanbul Yeni Yüzyıl University, Pharmacy Faculty, Department of Analytical Chemistry, Istanbul, Turkey \\ ${ }^{2}$ University of Health Science, Pharmacy Faculty, Department of Analytical Chemistry, İstanbul, Turkey
}

ORCID IDs of the authors: E.Ö. 0000-0002-5011-8344; D.T. 0000-0002-5279-0900; S.S. 0000-0002-0377-164X

Cite this article as: Ozdemir, E., Taskin, D., \& Sungur, S. (2020). Determination of sultamicillin in bulk and pharmaceutical preparations via derivatization with NBD-Cl by spectrophotometry. İstanbul Journal of Pharmacy, 50(1), 1-5.

\begin{abstract}
Background and Aims: A new sensitive and selective method for the determination of sultamicillin in bulk and pharmaceutical preparations has been developed.

Methods: The developed method is based on the derivatization of sultamicillin with 4-chloro-7-nitrobenzofurazan in pH 9.0 borate buffer at $70^{\circ} \mathrm{C}$ for $60 \mathrm{~min}$. The derivative was measured spectrophotometrically at $432 \mathrm{~nm}$ after extraction with chloroform.

Results: The method was validated by linearity, LOD, LOQ, accuracy, precision and recovery parameters. The linear range for sultamicillin was $10-50 \mu \mathrm{g} \cdot \mathrm{mL}^{-1}$ with a correlation coefficient of 0.9999 . The limit of detection (LOD) and limit of quantification (LOQ) were found to be 1.47 and $4.41 \mu \mathrm{g} / \mathrm{mL}^{-1}$, respectively.

Conclusion: The suggested method was validated, and can be applied for routine sultamicillin analysis in dosage formsfor industrial analysis.
\end{abstract}

Keywords: 4-chloro-7-nitrobenzofurazan, sultamicillin, spectrophotometry, validation

\section{INTRODUCTION}

Sultamicillin is a mutual prodrug of ampicillin and sulbactam. Chemically, it is a double ester in which ampicillin and sulbactam are linked via a methylene group (Ph. Eur. 6th. edition). It is used for the treatment of childhood pneumonia and other pediatric infections, as oral and parenteral preparations (Ganesh, Kalshetti \& Sanket, 2018). Sultamicillin tosylate dihydrate $\left(\mathrm{C}_{32} \mathrm{H}_{38} \mathrm{~N}_{4} \mathrm{O}_{12} \mathrm{~S}_{3} \cdot 2 \mathrm{H}_{2} \mathrm{O}\right)$ is 4-Methylbenzenesulphonate of methylene (2S,5R,6R)-6-[[(2R)-aminophenylacetyl]amino]-3,3-dimethyl7-oxo-4-thia-1 azabicyclo[3.2.0]heptane-2-carboxylate (2S,5R)-3,3-dimethyl-4,4,7-trioxo-4 ${ }^{6}$-thia-1- azabicyclo[3.2.0]heptane-2-carboxylate dihydrate (Ph. Eur. $6^{\text {th }}$. edition).

4-chloro-7-nitrobenzofurazan (NBD-Cl) is widely used as a chromogenic and fluorogenic reagent for the spectrophotometric and spectrofluorometric (Ayad et al, 2013; Azza et al., 2010; Darwish et al., 2008; El-Abd et al., 2013; El-Enany et al., 2009; Klimisch \& Stadler, 1974; Olgun et al., 2002; Shehata et al., 2006; Taha et al., 2006), chromatographic (Azza et al., 2010; El-Emam et al., 2004; Farshchia et al., 2009; Murray et al., 1983; Tatar Ulu, 2007; Tosunoglu et al., 1995; Yılmaz et al., 2016 ) determinations of pharmaceutical amines.

One spectrophotometric (Kshirsagar et al., 2018) anda few liquid chromatographic methods (El-Shanawani, 1998; Pajchel \& Tyski, 2002; Laviana, Fernandez, Bayod \& Blanco, 2003; Ganesh et al., 2018) have been reported previously for the quantitative 
determination of sultamicillin in pharmaceutical dosage form. In the method of Kshirsagar et al. 2018 absorbance measurements were made at $232 \mathrm{~nm}$ which is the absorption maximum of sultamicillin in methanol. For the assay of sultamicillin in pharmaceutical dosage forms, more selective analytical methods are required to avoid possible interferences of the excipients. So, in the present study, developing a new spectrophotometric method is aimed, involving derivatization with NBD-Cl, chloroform extraction and absorbance measurement of the derivative.

\section{MATERIALS AND METHODS}

\section{Reagents}

Sultamicillin tosylate dihydrate was kindly supplied by Deva (Istanbul, Turkey). and NBD-Cl was purchased from Sigma Aldrich (St. Louis, MO, USA). The 375 mg sultamicillin tablets were purchased from a local pharmacy. Other chemicals were provided by Merck (Darmstadt, Germany). All solvents used were of analytical grade.

\section{Apparatus}

A Shimadzu UV-mini 1240 PC-UV visible spectrophotometer with $1 \mathrm{~cm}$ quartz cell was used for all spectral measurements. $\mathrm{pH}$ measurements were carried out with a Jenco $6179 \mathrm{pH}$ meter.

\section{Preparation of standard and working stock solution}

The stock solution of sultamicillin was prepared in the concentration of $10 \mu \mathrm{g} \cdot \mathrm{mL}^{-1}$ by dissolving the appropriate amount of sultamicillin tosylate dihydrate in methanol. A working standard solution of sultamicillin containing $2 \mathrm{mg} \cdot \mathrm{mL}^{-1}$ was prepared by an appropriate dilution of the stock solution with methanol. A 2.0 mg.mL-1 NBD-Cl solution was prepared in methanol. The reagent solution was stable for two weeks if kept at $\pm 4^{\circ} \mathrm{C}$ (Taha et al., 2006). Borate buffers were prepared in the $\mathrm{pH}$ range of 8 to 10 .

\section{General analytical procedure}

25-125 $\mu \mathrm{L}$ aliquots of solution containing sultamicillin tosylate dihydrate equivalent to $50-250 \mu \mathrm{g}$ sultamicillin, were transferred into a series of reaction tubes. To each tube, $200 \mu \mathrm{L}$ of $\mathrm{pH}$ 9 borate buffer and $150 \mu \mathrm{L}$ of NBD-Cl solution $\left(2 \mathrm{mg} \cdot \mathrm{mL}^{-1}\right)$ were added and mixed in a vortex mixer. Then, these were kept at $70^{\circ} \mathrm{C}$ for 60 minutes, cooled to room temperature and acidified with $100 \mu \mathrm{L}$ of $0.1 \mathrm{M} \mathrm{HCl}$. After extracting with $2 \times 2 \mathrm{~mL}$ of chloroform, the extracts were combined and diluted to $5 \mathrm{~mL}$ with chloroform. The measure of absorbance was $432 \mathrm{~nm}$ against the blank solution.

\section{Procedure for tablets}

A portion of sultamicillin tablet powder obtained from 20 tablets, equivalent to $200 \mathrm{mg}$ sultamicillin, was transferred into a $100 \mathrm{~mL}$ calibrated flask, sonicated with $50 \mathrm{~mL}$ of methanol for 30 minutes, completed to its volume with methanol, mixed well and filtered. The first portion of the filtrate was rejected. A $75 \mu \mathrm{L}$ of aliquot of the solution was used for the determination.

\section{RESULTS}

NBD-chloride reacts with aliphatic primary and secondary amines to produce coloured and fluorescent derivatives. NBD derivatives have some advantages such as good stability, having an absorption maximum in the visible region and high signal/ noise ratios (Bahrami \& Mohammadi, 2006). Sultamicillin reacts with this reagent in alkaline buffer medium via its primary amino group yielding a yellow coloured product. Figure 1 shows the reaction between sultamicillin and NBD-Cl. The maximum absorbance of this derivative is at $432 \mathrm{~nm}$ in chloroform (Figure 2).
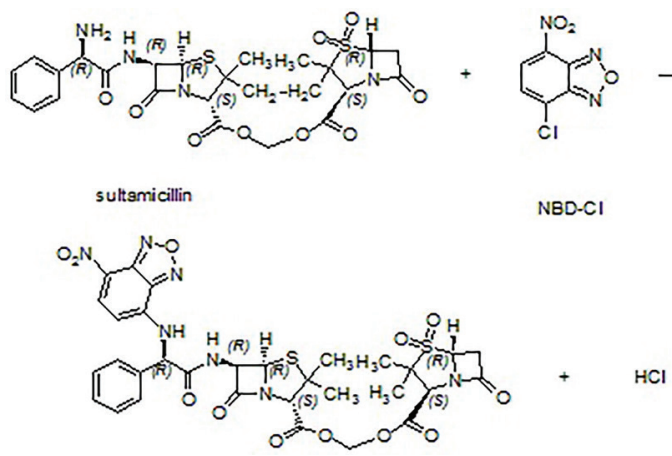

Figure 1. Reaction of sultamicillin with NBD-Cl.

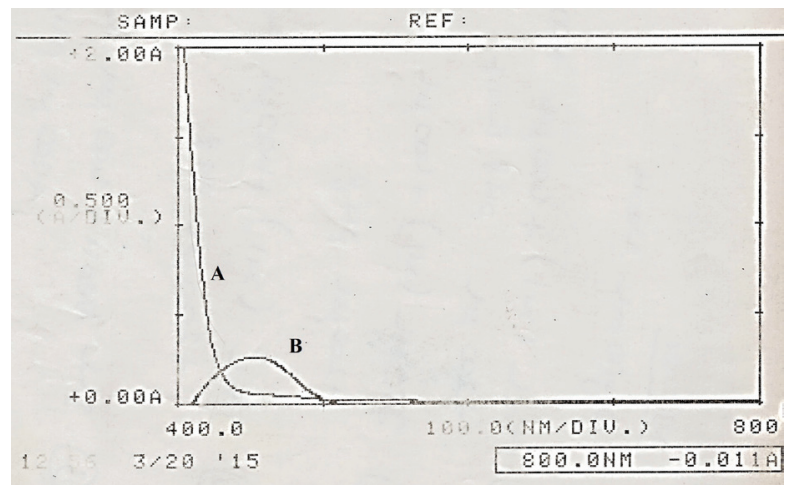

Figure 2. The absorption spectrum of sultamicillin-NBD derivative (B) and blank solution (A).

The conditions for the derivatization reaction were optimized. For this purpose, optimum $\mathrm{pH}$, temperature, reaction time, amount of the reagent, extraction solvent and wavelenght were studied.

Effect of the temperature and reaction time: In order to determine the optimum temperature and reaction time for the derivatization reaction, room temperature, and 40, 50, 60 and $70^{\circ} \mathrm{C}$ temperatures were studied for $10-70$ min intervals. The experimental results, shown in Figure 3 , indicated that maximum absorbance was obtained in $60 \mathrm{~min}$ at $70^{\circ} \mathrm{C}$.

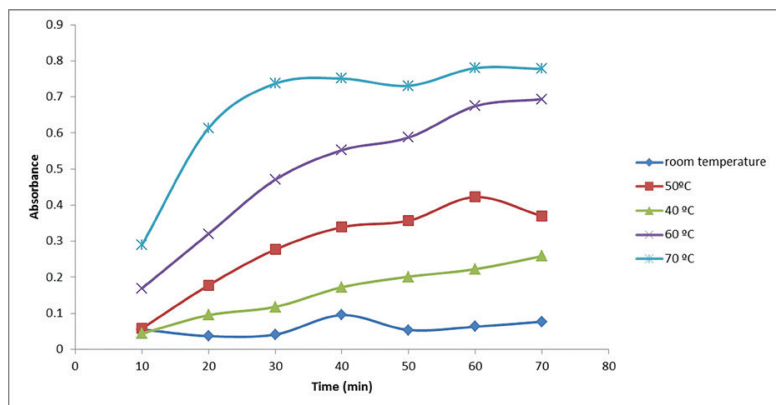

Figure 3. Effect of temperature and heating time on the derivatization (50 $\mathrm{gg} \cdot \mathrm{mL}^{-1}$ sultamicillin) . 
Effects of $\mathrm{pH}$ : The reaction between sultamicillin and NBD-Cl was studied in the $\mathrm{pH}$ range of 8 to 10 intervals to determine the best pH at which the reaction was carried out, and the optimal pH was found to be 9.0. Figure 4a shows the effect of $\mathrm{pH}$ on the derivatization. As it is seen, max. absorbance was obtained in a pH 9 borate buffer. In the derivatization reaction, excess NBD-Cl is hydrolized to NBD-OH, which is extractable into chloroform and has an absorption at $432 \mathrm{~nm}$. Therefore, the solution was acidified by adding $0.1 \mathrm{~mL}$ of $0.1 \mathrm{M} \mathrm{HCl}$ solution before the extraction step.

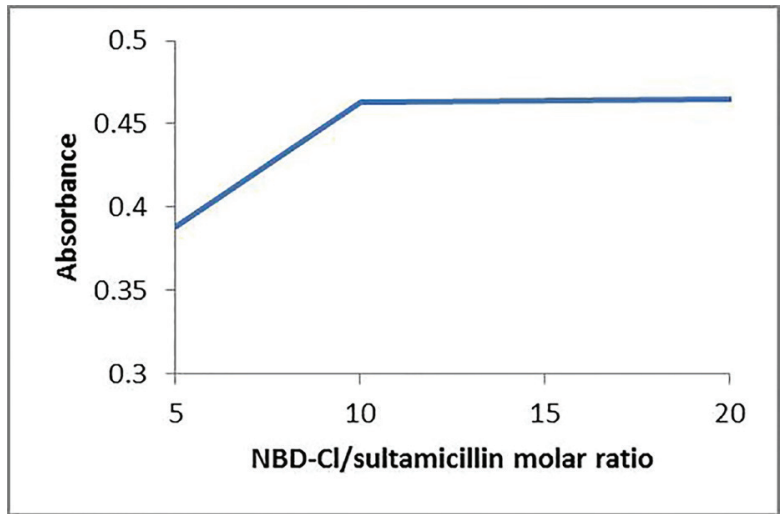

Figure 4a. Effect of reagent NBD concentration $\left(30 \mu \mathrm{g} \cdot \mathrm{mL}^{-1}\right)$.

Effects of reagent concentration: The amount of the reagent required for the maximum yield of the derivatization reaction, molar ratio of $\mathrm{NBD}-\mathrm{Cl} /$ sultamicillin ranging from 5 to 20, was studied. As it is shown in Figure 4b, 10 fold molar excess of the reagent is sufficient to complete the reaction.

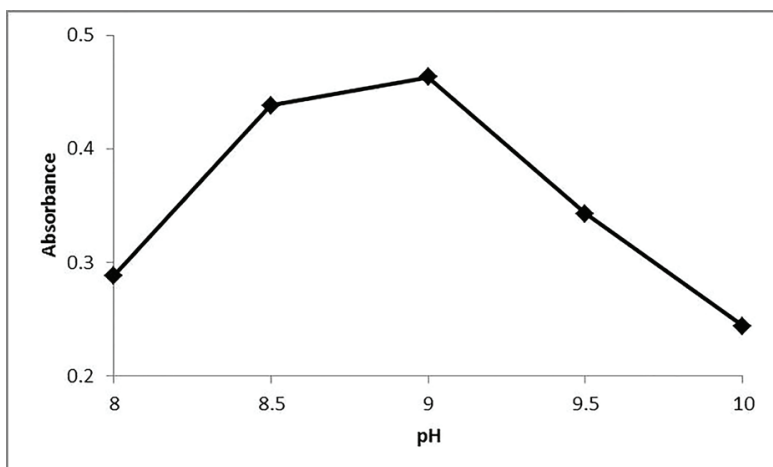

Figure 4b. Effect of $\mathrm{pH}$ on the derivatization reaction of sultamicillin $\left(30 \mu \mathrm{g} \cdot \mathrm{mL}^{-1}\right)$ with NBD-Cl.

Extraction solvent selection: Various organic solvents such as chloroform, ethyl acetate, methanol, dichloromethane, n-hexane were tested for the extraction of the derivative, and chloroform was chosen as the best solvent for the extraction, since the highest absorption intensity was observed in chloroform.

\section{Method validation}

The described method was validated as described in the International Conference on Harmonization (ICH) for drug applications (ICH Guideline, Q2(R1) 2005) in terms of linearity, LOD, $L O Q$, accuracy, precision and recovery.
Linearity.Under the optimum conditions, a linear relationship was obtained from five points covering the concentration range of 10-50 $\mathrm{gg} \cdot \mathrm{mL}^{-1}$. The regression equation of the calibration curve was $A=0.0157 C-0.004\left(R^{2}=0.9999\right)$. The calibration curve is shown in Figure 5.

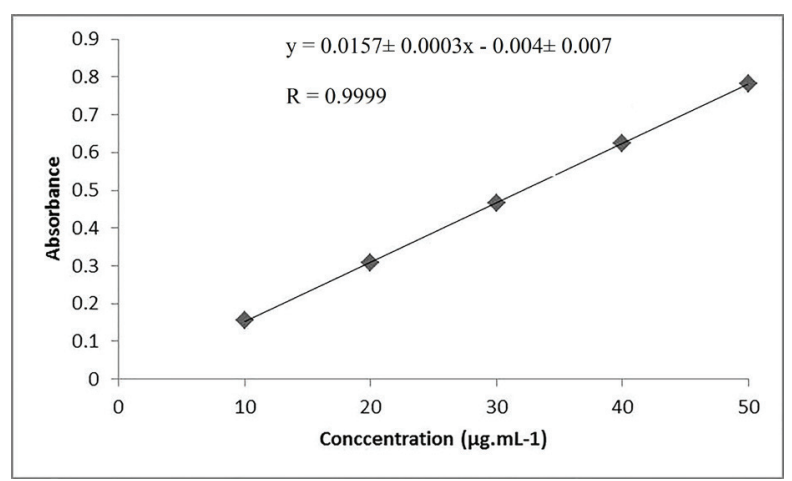

Figure 5. Calibration curve.

Limit of detection and limit of quantitation: The limit of dedection was calculated by $L O D=3.3 \sigma / S$, where $\sigma$ and $S$ are the standart deviation of the intercept and the slope of the calibration curve. The limit of quantification was calculated as $L O Q=10 \sigma / S$. LOD and LOQ values were found to be 1.47 and $4.41 \mu \mathrm{g} \cdot \mathrm{mL}^{-1}$ respectively. The statistical data are given in Table 1.

\section{Table 1. Optical characteristics and statistical data.}

\begin{tabular}{|lc|}
\hline Parameters & Values \\
\hline Maximum absorbance wavelength & $432 \mathrm{~nm}$ \\
Linear range & $10-50 \mu \mathrm{g} \cdot \mathrm{mL}^{-1}$ \\
The equation of the calibration curve & $\mathrm{A}=0.0157 \mathrm{C}-0.004$ \\
Slope $\pm \mathrm{SD}$ & $0.0157 \pm 0.0003$ \\
Intercept $\pm \mathrm{SD}$ & $-0.004 \pm 0.007$ \\
LOD & $1.47 \mu \mathrm{g} \cdot \mathrm{mL}^{-1}$ \\
LOQ & $4.41 \mu \mathrm{g} \cdot \mathrm{mL}^{-1}$ \\
\hline
\end{tabular}

Accuracy: The accuracy of the developed method was calculated using the standard addition method. The results are shown in Table 2. The recovery of the added pure drug was calculated as, \% Recovery- $\left[\left(C_{t}-C_{s}\right) / C_{a}\right] \times 100$, where $C_{t}$ is the total drug concentration measured after standard addition; $C_{\mathrm{s}^{\prime}}$ drug concentration in the formulation sample; and $\mathrm{Ca}$, drug concentration added to the formulation.

Table 2. Results for the determination of accuracy by analyzing sultamicillin in known concentration.

\begin{tabular}{lccc|}
$\begin{array}{l}\text { Concentra- } \\
\text { tion of drug } \\
\text { in formu- } \\
\text { lations, } \\
\mu \mathrm{g} \cdot \mathrm{mL}^{-1}\end{array}$ & $\begin{array}{c}\text { Concentra- } \\
\text { tion of pure } \\
\text { drug } \\
\text { added, } \\
\mu \mathrm{g} \cdot \mathrm{mL}^{-1}\end{array}$ & $\begin{array}{c}\text { Found, } \\
\mu \mathrm{g} \cdot \mathrm{mL}^{-1}\end{array}$ & $\begin{array}{c}\text { Recovery, } \\
\text { mean } \pm \mathrm{SD}\end{array}$ \\
\hline 30 & 15 & $45.23 \pm 0.74$ & $100.46 \pm 1.62$ \\
\hline
\end{tabular}


Precision: Precision of the developed method was assessed as repeatability (intraday) and intermediate precision (inter day), by analysing 6 replicate determinations at three different concentrations. The results are shown in Table 3.

\section{Table 3. Intraday and interday precisions of the method.}

\begin{tabular}{|cc|}
\hline Concentration $\left(\mu \mathrm{g} \cdot \mathrm{mL}^{-1}\right)$ & Precision (RSD\%) \\
\hline \multicolumn{2}{|c|}{ Intra-day } \\
\hline 10 & 1.69 \\
30 & 0.70 \\
50 & 1.89 \\
Inter-day & 1.10 \\
10 & 1.01 \\
30 & 0.85 \\
50 & \\
\hline
\end{tabular}

\section{Pharmaceutical application}

The proposed method was successfully applied to a sultamicillin pharmaceutical preparation. Sultamicillin $375 \mathrm{mg}$ tablets were analyzed by the proposed method and the official method (Ph. Eur. $6^{\text {th }}$. edition). The results obtained from both methods were compared statistically by the Student's t-test and Ftest in view of the precision and accuracy at a 95\% confidence level. Calculated $\mathrm{t}$ and $\mathrm{F}$ values did not exceed the theoretical tabulated values, indicating no significant difference between the proposed and the official methods.

The mean percentage recovery, relative to the label claims, obtained by use of the proposed method, ranged from 101.3\% to 101.6\% (Table 4).

\section{Table 4. Determination of sultamicillin in its pharmaceutical preparation by the proposed spectrophotometric and the official methods.}

\begin{tabular}{|c|c|c|c|c|}
\hline \multirow{2}{*}{$\begin{array}{l}\text { Pharmaceutical } \\
\text { preparation }\end{array}$} & \multicolumn{2}{|c|}{ Mean \pm SD } & \multirow[b]{2}{*}{$t$} & \multirow[b]{2}{*}{$F$} \\
\hline & $\begin{array}{l}\text { Proposed } \\
\text { method }\end{array}$ & $\begin{array}{l}\text { Official } \\
\text { method }\end{array}$ & & \\
\hline $375 \mathrm{mg}$ & $380.38 \pm 1.26$ & $380.16 \pm 0.90$ & 0.31 & 1.96 \\
\hline
\end{tabular}

The proposed method is based on the derivatization of sultamicillin with NBD-Cl. This method has alower linear concentration range, LOD and LOQ values compared to the previously reported spectrophotometric method of Kshirsagar and et. all. (Kshirsagar et al., 2018). The standard deviations and recoveries of the two methods are close to each other. On the other hand, the derivatization and extractionsteps make the proposed method more selective than the previous UV specrophotometric method. So, the proposed method is superior to theprevious method in view of the sensitivity and selectivity for the deter- mination of sultamicillin in pure, and its pharmaceutical dosage forms without any interference from excipients.

As it is seen in Table 5, the proposed method is superior to the previous method in view of the linear concentration range, LOD, LOQ and recovery. So, the proposed method is suitable for the determination of sultamicillin in pure, and its pharmaceutical dosage forms without any interference from excipients.

\section{Table 5. Comparison of analytical performances of} proposed and the previous methods.

\begin{tabular}{|lcc|}
\hline Parameters & $\begin{array}{c}\text { Proposed } \\
\text { method }\end{array}$ & $\begin{array}{c}\text { Previous method (Ph. } \\
\text { Eur. 6 }\end{array}$. Edition) \\
\hline Linear range $(\mu \mathrm{g}$. & $10-50$ & $20-100$ \\
$\left.\mathrm{~mL}^{-1}\right)$ & 1.47 & 3.67 \\
LOD $\left(\mu \mathrm{g} \cdot \mathrm{mL}^{-1}\right)$ & 4.41 & 11.18 \\
LOQ $\left(\mu \mathrm{g} \cdot \mathrm{mL}^{-1}\right)$ & 100.46 & 99.50 \\
Recovery $(\%)$ & & \\
\hline
\end{tabular}

\section{CONCLUSION}

This paper presents the development of a sensitive and simple spectrophotometric method to determine sultamicillin after its derivatization with a NBD-Cl reagent. Compared with previous methods, this method gave the highest sensitivity in measuring low sultamicillin concentrations. The suggested method might be used for routine sultamicillin analysis in dose forms. The method was validated and can be easily adapted for industrial analysis.

Peer-review: Externally peer-reviewed.

Author Contributions: Conception/Design of Study- E.Ö., S.S., D.T.; Data Acquisition-E.Ö., D.T.; Data Analysis/Interpretation- E.Ö., S.S., D.T.; Drafting Manuscript- E.Ö.; Critical Revision of Manuscript- E.Ö., S.S., D.T.; Final Approval and Accountability- E.Ö., S.S., D.T.; Technical or Material Support- E.Ö., D.T.; Supervision- E.Ö.

Conflict of Interest: The authors have no conflict of interest to declare.

Financial Disclosure: Authors declared no financial support.

\section{REFERENCES}

- $\quad$ Ayad, M. M., Hosny, M. M., \& Sharaf, Y. A. (2013). Application of 4-chloro-7-nitrobenzofurazan for the analysis of propafenone and diltiazem hydrochlorides using kinetic spectrophotometric and spectrofluorimetric methods. European Journal of Chemistry, 4(1), 35-43.

- $\quad$ Azza, H. R., Salwa, R. E., Gamal, A. S., \& Fardous, A. M. (2010). Spectophotometric method for determination of certain cephalosporins using 4-chloro-7-nitrobenzo-2-oxa-1, 3-diazole (NBD-Cl). Natural Science, 2, 828-840.

- Bahrami, G., \& Mohammadi, B. (2006). Sensitive microanalysis of gabapentin by high-performance liquid chromatography in human serum using pre-column derivatization with 4-chloro-7-nitrobenzofurazan: Application to a bioequivalence study. Journal of Chromatography B: Analytical Technologies in the Biomedical and Life Sciences, 837, 24-28. 
- Darwish, I., Mahmoud, A., Khalil, N. Y. (2008). Nonextractive Procedure and Precolumn Derivatization with 7-Chloro-4-nitrobenzo-2-oxa-1,3-diazole for Trace determination of trimetazidine in plasma by high-performance liquid chromatography with fluorescence detection. Journal-Association of Official Analytical Chemists, 91(5), 1037-1044.

- El-Emam, A. A., Hansen, S. H., Moustafa, M. A., El-Ashry, S. M., \& El-Sherbiny, D. T. (2004). Determination of lisinopril in dosage forms and spiked human plasma through derivatization with 7-chloro-4-nitrobenzo-2-oxa-1,3-diazole (NBD-Cl) followed by spectrophotometry or HPLC with fluorimetric detection. Journal of Pharmaceutical and Biomedical Analysis, 34, 35-44.

- El-Enany, N., Ahmida, N., \& Bela, F. (2009). Spectrofluorimetric and spectrophotometric determination of oxamniquine in pharmaceuticals and biological fluids via derivatization with 7-chloro4-nitrobenzo-2-oxa-1,3-diazole (NBD-Cl). Journal-Chinese Chemical Society Taipei, 56, 485-492.

- $\quad$ El-Abd, H. S., Colyer, C. L., Hassan, W. S., \& Shalaby, A. J. (2013). Utility of 4-chloro-7-nitrobenzofurazan (NBD-Cl) for the Spectrophotometric and spectrofluorometric determination of several antihistamine and antihypertensive drugs. Journal-Association of Official Analytical Chemists, 96(5), 968-75.

- El-Shanawani, A. A. (1998). HPLC determination of sulbactam, sultamicillin tosylate, cefaclor, ampicillin and cefoperazone in pharmaceutical preparations. Acta Poloniae Pharmaceutica-Drug Research, 55(1), 15-19. European Pharmacopoeia, 6.0, 3003

- Farshchia, A., Ghiasia, G., \& Bahramia, G. (2009). High Performance Liquid Chromatography Determination of Sertraline in Human. Iranian Journal of Pharmaceutical Sciences, 5(3), 171-178.

- Ganesh, B. G., Kalshetti, M. S., \& Sanket, A. K. (2018). Analytical method development and validation for sultamicillin tosylate dihydrate in bulk and pharmaceutical dosage forms by RP-HPLC. International Journal for Pharmaceutical Research Scholars, 7, 1-2.

- International Conference on Harmonization. $\mathrm{ICH}$. Validation of analytical procedures: text and methodology Q2 R1. Geneva: International Conference on Harmonization; 2005. [cited 2018 Mar 4] Available from: http://academy.gmp compliance.org/ guidemgr/files/Q2(R1).PDF

- Klimisch, H. J., \& Stadler, L. (1974).Fluorimetric determination of nitrosamines after acid catalysed denitrification and obtaining of a derivative with 7 chloro 4 nitrobenzo 2 oxa 1,3 diazole. Journal of Chromatography A, 90, 223-225.
Kshirsagar, S. A., Mane, S. B., Hanchate, Y. S., Katte, A. S., Rhumane, M. B., Mirza, N. N. ... Mudke, R. P. (2018). UV spectrophotometrıc method development and validation for determination of sultamicillintosylate in API and in pharmaceutical dosage form. Australian Journal of Science and Technology, 9, 7657-7662.

- Laviana, L., Fernández, M. F., Bayod, M., \& Blanco, D. (2003). HPLC for in-process control in the production of sultamicillin. Journal of Pharmaceutical and Biomedical Analysis,31(2), 321-328.

- Murray, G. M., \& Sepaniak, M. J. (1983). HPLC laser fluorometric determination of amines in beer. Journal of Liquid Chromatography, 6, 931-938.

- Olgun, N., Erturk, S., \& Atmaca, S. (2002). Spectrofluorimetric and spectrophotometric methods for the determination of vigabatrin in tablets. Journal of Pharmaceutical and Biomedical Analysis, 29, $1-5$.

- $\quad$ Pajchel, G., \& Tyski, S. (2002). Application of micellar electrokinetic chromatography to the determination of sultamicillin in oral pharmaceutical preparations. Journal of Chromatography A, 979, 315-321.

- $\quad$ Shehata, M. A., El-Sayed, G. M., \& Abdel-Fattah, L. E. (2006). Utilization of 4-chloro-7-nitro-2,1,3-benzoxadiazole (NBD-Cl) for kinetic spectrophotometric assay of befunolol hydrochloride in its pharmaceutical formulation. Journal - Association of Official Analytical Chemists, 89(3), 646-650.

- Taha, E. A., Salama, N. N., \& Fattah, Lel-S. (2006). Spectrofluorimetric and spectrophotometric stability-indicating methods for determination of some oxicams using 7-chloro-4-nitrobenz2oxa-1,3-diazole (NBD-Cl). Chemical \& Pharmaceutical Bulletin, 54, 653-658.

- Tatar-Ulu, S. (2007). Development of an HPLC method for the determination of mexiletine in human plasma and urine by solidphase extraction. Talanta, 72(3),1172-1177.

- Tosunoglu, S., \& Ersoy, L. (1995). Determination of baclofen in human plasma and urine by high-performance liquid chromatography with fluorescence detection. Analyst, 120, 373-375.

- $\quad$ Yılmaz, E. M., Aydoğmuş, Z., \& Aboul-Eneın, H. Y. (2016). Determination of nilotinib in spiked plasma, urine, and capsules by highperformance liquid chromatography with fluorimetric detection. Acta Chromatographica, 28, 313-331. 